University of Nebraska - Lincoln

DigitalCommons@University of Nebraska - Lincoln

Faculty Papers and Publications in Animal

Science

Animal Science Department

December 2002

\title{
Estimates of parameters between direct and maternal genetic effects for weaning weight and direct genetic effects for carcass traits in crossbred cattle
}

\author{
R. K. Splan \\ University of Nebraska-Lincoln \\ Larry V. Cundiff \\ University of Nebraska-Lincoln, Icundiff2@unl.edu \\ M. E. Dikeman \\ Kansas State University, Manhattan \\ L. Dale Van Vleck \\ University of Nebraska-Lincoln, dvan-vleck1@unl.edu
}

Follow this and additional works at: https://digitalcommons.unl.edu/animalscifacpub

Part of the Animal Sciences Commons

Splan, R. K.; Cundiff, Larry V.; Dikeman, M. E.; and Van Vleck, L. Dale, "Estimates of parameters between direct and maternal genetic effects for weaning weight and direct genetic effects for carcass traits in crossbred cattle" (2002). Faculty Papers and Publications in Animal Science. 231.

https://digitalcommons.unl.edu/animalscifacpub/231

This Article is brought to you for free and open access by the Animal Science Department at DigitalCommons@University of Nebraska - Lincoln. It has been accepted for inclusion in Faculty Papers and Publications in Animal Science by an authorized administrator of DigitalCommons@University of Nebraska - Lincoln. 


\title{
Estimates of parameters between direct and maternal genetic effects for weaning weight and direct genetic effects for carcass traits in crossbred cattle ${ }^{1}$
}

\author{
R. K. Splan*2, L. V. Cundiff $\dagger$, M. E. Dikeman $§$, and L. D. Van Vleck $\dagger \ddagger^{3}$ \\ *University of Nebraska, Lincoln, and †USDA, ARS, Roman L. Hruska U.S. Meat Animal Research Center, \\ $†$ Clay Center 68933-0166 and $\ddagger$ Lincoln, NE 68583-0908; and §Department of Animal Science and Industry, \\ Kansas State University, Manhattan 66506-0201
}

\begin{abstract}
Estimates of heritabilities and genetic correlations were obtained for weaning weight records of 23,681 crossbred steers and heifers and carcass records from 4,094 crossbred steers using animal models. Carcass traits included hot carcass weight; retail product percentage; fat percentage; bone percentage; ribeye area; adjusted fat thickness; marbling score, WarnerBratzler shear force and kidney, pelvic and heart fat percentage. Weaning weight was modeled with fixed effects of age of dam, sex, breed combination, and birth year, with calendar birth day as a covariate and random direct and maternal genetic and maternal permanent environmental effects. The models for carcass traits included fixed effects of age of dam, line, and birth year, with covariates for weaning and slaughter ages and random direct and maternal effects. Direct and mater-
\end{abstract}

nal heritabilities for weaning weight were $0.4 \pm 0.02$ and $0.19 \pm 0.02$, respectively. The estimate of directmaternal genetic correlation for weaning weight was negative $(-0.18 \pm 0.08)$. Heritabilities for carcass traits of steers were moderate to high (0.34 to 0.60). Estimates of genetic correlations between direct genetic effects for weaning weight and carcass traits were small except with hot carcass weight (0.70), ribeye area (0.29), and adjusted fat thickness (0.26). The largest estimates of genetic correlations between maternal genetic effects for weaning weight and direct genetic effects for carcass traits were found for hot carcass weight $(0.61)$, retail product percentage $(-0.33)$, fat percentage $(0.33)$, ribeye area (0.29), marbling score (0.28) and adjusted fat thickness (0.25), indicating that maternal effects for weaning weight may be correlated with genotype for propensity to fatten in steers.

Key Words: Crossbreeding, Genetic Correlation, Heritability

(C2002 American Society of Animal Science. All rights reserved.

J. Anim. Sci. 2002. 80:3107-3111

\section{Introduction}

In recent years, the beef industry has moved toward a system of value-based marketing to satisfy consumer preferences for meat quality. Breed associations have responded by incorporating carcass EPD into national cattle evaluations, in addition to EPD previously calculated for growth and reproductive traits.

Selection for aggregate genetic improvement is most effective when relationships among the traits selected

\footnotetext{
${ }^{1}$ Published as paper no. 13486, Journal Ser., Nebraska Agric. Res. Div., Univ. of Nebraska, Lincoln 68583-0908 and contribution no. 99468-J, Kansas Agric. Exp. Sta. Manhattan 66506-4008.

${ }^{2}$ Current address: 3450 Litton Reaves Hall, Virginia Tech, Blacksburg 24061-0306 (phone: 540/231-4740; fax: 540/231-3010; E-mail: rsplan@vt.edu).

${ }^{3}$ Correspondence: A218 Animal Sciences, University of Nebraska, Lincoln 68583-0908 (phone: 402/472-6010; fax: 402/472-6362; E-mail: lvanvleck@unlnotes.unl.edu).

Received September 4, 2001.

Accepted July 24, 2002.
}

are known (Mohuiddin, 1993). An estimate of maternal genetic ability for weaning weight has been included in genetic evaluation programs for some time, but relatively little is known about its relationship to carcass characteristics (Green, 1996; Koots et al., 1994), despite important contributions to this area (MacNeil et al., 1984; Crews and Kemp, 1999; Shanks et al., 2000). Correlations between total genetic effects for weaning weight and some economically important carcass traits have, in some cases, been favorable (Koch, 1978; Koots et al., 1994) and may represent opportunities for increased productivity. If genetic antagonisms exist, however, they may hinder effective selection and reduce profitability. The objective of this study, therefore, was to estimate correlations among direct and maternal genetic effects for weaning weight and direct genetic effects for carcass traits in beef cattle.

\section{Materials and Methods}

Data were obtained from Cycles I-IV of the Germ Plasm Evaluation project at the Roman L. Hruska U.S. 
Meat Animal Research Center in Clay Center, NE. Calves in Cycle I were born from 1970 through 1972 and were the result of AI matings of Hereford, Angus, Jersey, South Devon, Limousin, Charolais, and Simmental sires with Hereford and Angus dams. Cycle II calves were born in 1973 and 1974 and were the result of mating Hereford and Angus sires, including reference sires used in Cycle I, and Red Poll, Brown Swiss, Gelbvieh, Maine Anjou, and Chianina sires to Hereford, Angus, Red Poll, and Brown Swiss dams. In Cycle III, calves were born in 1975 and 1976 and resulted from AI mating of Hereford and Angus bulls, again including reference sires from Cycle I, and Brahman, Sahiwal, Pinzgauer, and Terentaise bulls to Hereford and Angus dams. In Cycle IV, calves were produced from 1986 to 1990 from AI matings of Angus and Hereford bulls (current sires born from 1983 to 1985 and reference sires born from 1963 to 1970) and Longhorn, Piedmontese, Charolais, Salers, Galloway, Nelore, and Shorthorn bulls to Hereford and Angus dams. In Cycle IV, after the 45-d AI period, open females were placed in singlesire breeding pastures for $21 \mathrm{~d}$ to be bred by natural service to Charolais, 7/8 Gelbvieh, and 7/8 Pinzgauer bulls. These matings were used to increase ties to previous cycles. Details of breeding and preweaning calf management were described by Smith et al. (1976), and Gregory et al. (1978; 1979a), and Cundiff et al. (1998).

The management protocol for $\mathrm{F}_{1}$ heifers was to produce first calves at $2 \mathrm{yr}$ of age. Postweaning heifer management has been described by Laster et al. (1976; 1979), Gregory et al. (1979b), and Thallman et al. (1999). Heifers born in Cycle I were bred by AI to Hereford, Angus, Holstein, South Devon, and Brahman sires. Cycle II heifers were mated by AI to Hereford, Angus, Brahman, and Santa Gertrudis sires. In the final two cycles, all heifers were bred by natural service to Red Poll bulls, and females older than 2 yr were subsequently bred by natural service to Simmental sires in multibull breeding pastures.

Weaning weights (WWT, $\mathrm{n}=23,681$ ) included both F1 males and females, as well as calves of F1 females. Weaning weights were adjusted to $205 \mathrm{~d}$ by adding to birth weight the product of 205 and average daily gain to actual day of weaning (BIF, 1996).

After weaning, steers were allocated to replicated pens and fed in groups according to sire breed. A postweaning adjustment period of 25 to $40 \mathrm{~d}$ was followed by an average of 262 total days on feed. Each year, steers were serially slaughtered in commercial packing plants in three or four groups over a period of 56 to 84 d. Koch et al. $(1976 ; 1979 ; 1982)$ and Wheeler et al. (1996) provide details of postweaning management and slaughter protocol.

At slaughter, hot carcass weight (HCWT) was recorded for each steer. After a 24-h chill, ribeye area (REA); kidney, pelvic, and heart fat percentage (KPH), adjusted fat thickness (AFAT), and marbling score (MARB) were determined. Marbling score was scored on a 100-point scale within each of seven categories
Table 1. Summary statistics (number, N; mean standard deviation, SD) for weaning weight and carcass traits

\begin{tabular}{lrrr}
\hline \hline Trait & $\mathrm{N}$ & $\mathrm{Mean}^{\mathrm{a}}$ & $\mathrm{SD}^{\mathrm{a}}$ \\
\hline Weaning weight, kg & 23,681 & 183.10 & 30.73 \\
Hot carcass weight, kg & 4,088 & 301.40 & 41.06 \\
Retail product percentage, \% & 3,708 & 68.70 & 4.10 \\
Fat percentage, \% & 3,708 & 18.42 & 4.72 \\
Bone percentage, \% & 3,704 & 12.88 & 1.07 \\
Ribeye area, cm & \\
Adjusted fat thickness, cm & 4,094 & 73.48 & 9.03 \\
Kidney, pelvic, and heart fat & 4,091 & 1.22 & 0.49 \\
percentage, \% & & & \\
Marbling score, score & 3,707 & 3.95 & 1.13 \\
Warner-Bratzler shear force, kg & 3,696 & 5.29 & 1.00 \\
& 3,705 & 4.15 & 1.53 \\
\hline
\end{tabular}

${ }^{a}$ Unadjusted mean and standard deviation.

(AMSA, 2001). Fat thickness, measured at the 12th rib, was adjusted visually for distortion from hide pull and atypical fat cover distribution over the chuck, round, and other parts of the carcass. For Cycles I through III (1970 through 1976), the right side of each carcass was processed at Kansas State University, Manhattan, KS. For Cycle IV, processing was performed at the U.S. Meat Animal Research Center, Clay Center, NE. Carcass halves were processed into boneless, closely trimmed retail cuts, fat trim, and bone. Weights from retail product, fat trim, and bone were converted into percentages of actual carcass weights (RET, FAT, and BON, respectively). Longissimus dorsi steaks were aged for $7 \mathrm{~d}$ and frozen for future evaluation. After thawing $24 \mathrm{~h}$ at 2 to $4^{\circ} \mathrm{C}$, the steaks were prepared for Warner-Bratzler shear force tests. Across all four cycles, steaks were cut $2.54 \mathrm{~cm}$ thick, and within location, a consistent protocol to determine shear force values was used. For evaluations at Kansas State University, steaks were cooked to an internal temperature of $65^{\circ} \mathrm{C}$, cooled at room temperature for $30 \mathrm{~min}$, and eight $1.27-\mathrm{cm}$ cores were removed. For evaluations at the U.S. Meat Animal Research Center, steaks were cooked to an internal temperature of $70^{\circ} \mathrm{C}$, stored at $5^{\circ} \mathrm{C}$ for $24 \mathrm{~h}$, and six 1.27-cm cores were removed. WarnerBratzler shear force (WBSF) was measured by shearing each core with an Instron 1132/Microcon II United Testing Instrument (Instron, Canton, MA) equipped with a Warner-Bratzler shear device (Wheeler et al., 1996).

Table 1 shows the summary statistics for weaning weight and carcass traits after elimination of outliers greater than four standard deviations from the mean.

\section{Statistical Analyses}

Fixed factors for models for all traits were determined through preliminary analyses using procedure GLM of SAS (SAS Inst. Inc., Cary, NC). Fixed factors (main effects and interactions) and covariates were tested and removed from the model if found nonsignificant $(P>$ 0.01 , with nonsignificant effects rejected sequentially, 
Table 2. Estimates and standard errors (SE) of estimates of direct $\left(\mathrm{h}_{\mathrm{d}}^{2}\right)$ and maternal $\left(\mathrm{h}_{\mathrm{m}}^{2}\right)$ heritabilities and direct-maternal genetic correlation $\left(\mathrm{r}_{\mathrm{d}, \mathrm{m}}\right)$ for weaning weight

\begin{tabular}{lr}
\hline \hline Parameter & Estimate (SE) \\
\hline $\mathrm{h}_{\mathrm{d}}^{2}$ & $0.14 \pm 0.02$ \\
$\mathrm{~h}_{\mathrm{m}}^{2}$ & $0.19 \pm 0.02$ \\
$\mathrm{r}_{\mathrm{d}, \mathrm{m}}$ & $-0.18 \pm 0.08$ \\
\hline
\end{tabular}

and those effects with greatest $p$-values rejected first. Fixed factors for weaning weight were age of dam, year of birth, sex, and breed composition, along with a covariate for calendar birth day. Fixed factors for carcass traits were age of dam, year of birth, and line, with age at weaning and age at slaughter as linear covariates.

Animal models were used for final analyses of all data. The model for weaning weight also contained a random maternal genetic effect, as well as the uncorrelated random effect of maternal permanent environment. Models for carcass traits did not contain a maternal genetic component but included a maternal effect as an uncorrelated random effect to account jointly for maternal genetic and permanent environmental effects of the dam. The multiple-trait derivative-free restricted maximum likelihood (MTDFREML) suite of programs (Boldman et al., 1995) was used for univariate and bivariate analyses for all traits. Iterations for each trait were stopped when the variance of twice the negative logarithm of the likelihood function $(-2 \log \mathrm{L})$ was less than $1 \times 10^{-9}$ for single trait analyses or $1 \times 10^{-6}$ for pairwise analyses. Initial starts used variance component estimates based on the literature or previous research with this dataset, and each subsequent restart used starting values from the previous run. Convergence was declared when differences in $-2 \log \mathrm{L}$ were small (generally less than 0.01), and ratios of variance components as a function of phenotypic variance and correlations changed by less than 0.01 . Associated standard errors for estimates in single-trait analyses were estimated using an average information algorithm derived by Johnson and Thompson (1995) as implemented by Dodenhoff et al. (1998).

\section{Results and Discussion}

Estimates of heritability and direct-maternal correlations for weaning weight are shown in Table 2.

The estimate of direct heritability for weaning weight was slightly less than expected, though not outside the range of values reported by the comprehensive review of Mohuiddin (1993) for similar analyses with animal models ( 0.14 to 0.58$)$. The estimate of maternal heritability was only slightly greater than the estimate for direct heritability. Mohuiddin (1993) reported that maternal heritabilities for weaning weight tended to be lower than direct heritabilities, indicating a greater genetic influence of the calf than its dam for the trait. Our estimates for direct and maternal heritability and direct-maternal correlation are similar to those reported by Koch et al. (1994), using Hereford data with an animal model including random effects of maternal, direct, and permanent environmental effects. Most of the estimates of direct-maternal correlation reported by Mohuiddin (1993) were negative, although they ranged from -0.78 to 0.25 .

Negative estimates of direct-maternal genetic covariance have been reported for many beef cattle populations and are included in the national genetic evaluations of many breed associations (e.g., Lee and Pollak, 1997).

Estimates of heritability for carcass traits, proportion of phenotypic variance due to maternal effects, and direct and maternal genetic correlations with weaning weight are shown in Table 3. Estimates of heritability for carcass traits were moderate to large. Generally, estimates were consistent with previous literature (Koots et al., 1994). Variances due to maternal effects as proportions of phenotypic variance were not significantly different from zero for most traits and were small for HCWT, RET, and FAT.

Few literature estimates are available regarding genetic correlations between direct and maternal genetic effects for weight traits and direct effects for carcass traits. Crews and Kemp (1999) obtained positive estimates of genetic correlation between direct genetic effects for weaning weight and hot carcass weight $(0.28$ \pm 0.20 ), a smaller estimate than found here (0.70). However, the estimate of the genetic correlation between the maternal component of weaning weight and direct component for hot carcass weight reported by Crews and Kemp (1999) was similar $(0.64 \pm 0.12)$ to our estimate (0.61).

Several authors have estimated correlations between growth and carcass traits, but without fitting maternal effects to the models for growth traits. Gregory et al. (1995) found a moderate positive genetic correlation between weaning weight and carcass weight $(0.42 \pm$ 0.18 ) from data involving both purebred and composite animals.

Estimates of genetic correlations between direct and maternal weaning weight and percent lean yield were not significantly different from zero in the study by Crews and Kemp (1999) $(0.15 \pm 0.20$ and $0.03 \pm 0.19$, respectively), while estimates between direct and maternal WWT and RET in our study were negative $(-0.12$ and -0.33 , respectively). However, percent lean yield as used by Crews and Kemp (1999) was calculated from other characteristics, such as hot carcass weight and yield grade, and was not directly measured. Gregory et al. (1995) reported a negative estimate of genetic correlation between RET and WWT $(-0.28 \pm 0.21)$ and a positive genetic correlation between $\mathrm{BON}$ and WWT $(0.37 \pm 0.30)$. Here, estimates of genetic correlations were negative and small with WWT $(-0.13$ and -0.09 , respectively). 
Table 3. Estimates of direct heritability $\left(\mathrm{h}^{2}\right)$, proportion of phenotypic variance due to maternal effects $\left(c^{2}\right)$, and associated standard errors (SE) for carcass traits and direct $\left(r_{d}\right)$ and maternal $\left(r_{m}\right)$ genetic correlations with weaning weight

\begin{tabular}{lccrr}
\hline \hline Trait & $\mathrm{h}^{2}(\mathrm{SE})$ & $\mathrm{c}^{2}$ & \multicolumn{1}{c}{$\mathrm{r}_{\mathrm{d}}$} & $\mathrm{r}_{\mathrm{m}}$ \\
\hline Hot carcass weight & $0.49 \pm 0.06$ & $0.04 \pm 0.03$ & 0.70 & 0.61 \\
Retail product percentage & $0.58 \pm 0.07$ & $0.04 \pm 0.03$ & -0.12 & -0.33 \\
Fat percentage & $0.49 \pm 0.07$ & $0.06 \pm 0.03$ & 0.14 & 0.33 \\
Bone percentage & $0.48 \pm 0.07$ & $0.00 \pm 0.03$ & -0.13 & -0.08 \\
Ribeye area & $0.58 \pm 0.07$ & $0.00 \pm 0.03$ & 0.29 & 0.29 \\
Adjusted fat thickness & $0.46 \pm 0.07$ & $0.00 \pm 0.03$ & 0.26 & 0.29 \\
Kidney, pelvic, and heart & & & & 0.19 \\
$\quad$ fat percentage & $0.60 \pm 0.07$ & $0.00 \pm 0.03$ & 0.17 & 0.28 \\
Marbling score & $0.35 \pm 0.06$ & $0.03 \pm 0.03$ & -0.12 & -0.06 \\
$\quad$ Warner-Bratzler shear & & & & 0.05 \\
$\quad$ force & $0.34 \pm 0.07$ & $0.00 \pm 0.03$ & &
\end{tabular}

Estimates of genetic correlations for direct and maternal effects of WWT with AFAT were moderate and positive (0.26 and 0.25 , respectively). Gregory et al. (1995) reported a positive genetic correlation between WWT and AFAT (0.23 \pm 0.23$)$. Crews and Kemp (1999) estimated genetic correlations between direct and maternal components of WWT and REA to be positive $(0.34$ \pm 0.17 and $0.18 \pm 0.18$, respectively). Our estimates were of similar magnitude ( 0.29 and 0.29 , respectively). Gregory et al. (1995) also reported a positive genetic correlation between direct genetic effects for WWT and REA $(0.45 \pm 0.21)$.

Estimates of genetic correlation between KPH and the direct and maternal genetic effects for WWT were small to moderate and positive. Genetic correlation between direct effect of WWT and MARB was estimated to be negative $(-0.12)$, while the estimate of genetic correlation involving the maternal effect for WWT and direct effect for MARB was positive (0.28). Gregory et al. (1995) reported a positive genetic correlation between WWT and MARB $(0.27 \pm 0.18)$.

Near-zero estimates of genetic correlations were found between direct and maternal effects of WWT and WBSF. Gregory et al. (1995) reported similar nonsignificant genetic correlations between WWT and WBSF or tenderness score.

Selection for increased direct genetic value for WWT would be expected to increase HCWT, FAT, AFAT, $\mathrm{REA}$, and KPH, to decrease RET, BON, and MARB, and to have little effect on WBSF. Emphasis on maternal milk or maternal effects on WWT may lead to positive correlated responses in HCWT, FAT, AFAT, REA, MARB, and KPH, with little effect on WBSF. All genetic correlations with carcass traits that were positive for direct genetic effects for WWT were also positive for maternal genetic effects, except for MARB, RET, and BON, which all had small positive estimates of genetic correlations with direct effects for WWT. The estimates of genetic correlations between maternal effects of WWT and carcass traits were moderate to large for carcass traits involving fatness or increased retail weight as a function of increased body weight.
Previous work has shown genetic correlations between weaning weight and some carcass traits to be moderate to large, and results from this study indicate that when the genetic effect for weaning weight is partitioned into direct and maternal components, genetic maternal ability for weaning weight may be correlated with some of the carcass traits studied.

\section{Implications}

To meet demand for quality beef, seedstock and commercial producers need to consider not only growth, maternal ability, and production efficiency in selection decisions but also carcass traits. Because most of the correlations between maternal genetic effects for weaning weight are not large in magnitude, selection for carcass traits would not be expected to result in important changes in maternal ability. Selection for carcass traits, including tenderness, would be expected to be effective because of moderate to high heritability. Selection to increase maternal or direct weaning weight would be expected to increase carcass weight, ribeye area, and fat thickness but would not be expected to affect tenderness. Selection for maternal weaning weight only would be expected to increase carcass fat percentage and marbling and decrease retail product percentage. Selection for direct weaning weight only would be expected to slightly decrease marbling and retail product percentage.

\section{Literature Cited}

AMSA. 2001. Meat Evaluation Handbook. American Society of Animal Science. Savoy, IL.

BIF. 1996. Guidelines for Uniform Beef Improvement Programs. 7th ed. Northwest Research Extension Center, Colby, KS.

Boldman, K. G., L. A. Kriese, L. D. Van Vleck, C. P. Van Tassell, and S. D. Kachman. 1995. A manual for use of MTDFREML. A set of programs to obtain estimates of variances, and covariances [draft]. USDA, ARS. Clay Center, NE.

Crews, D. H., Jr., and R. A. Kemp. 1999. Contributions of preweaning growth information and maternal effects for prediction of carcass trait breeding values among crossbred beef cattle. Can. J. Anim. Sci. 79:17-25. 
Cundiff, L. V., K. E. Gregory and R. M. Koch. 1998. Germplasm evaluation in beef cattle. Cycle IV: Birth and weaning traits. J. Anim. Sci. 76:2528-2535.

Dodenhoff, J., L. D. Van Vleck, S. D. Kachman, and R. M. Koch. 1998. Parameter estimates for direct, maternal and grandmaternal genetic effects for birth and weaning weight in Hereford cattle. J. Anim. Sci. 76:2521-2527.

Green, R. 1996. Carcass EPD's: Put up or shut up!! Pages 57-71 in Proc. Beef Improvement Fed. 28th Annual Mtg. Birmingham, AL.

Gregory, K. E., L. V. Cundiff, and R. M. Koch. 1995. Genetic and phenotypic (co)variances for growth and carcass traits of purebred and composite populations of beef cattle. J. Anim. Sci. 73:1920-1926.

Gregory, K. E., L. V. Cundiff, G. M. Smith, D. B. Laster, and H. A. Fitzhugh, Jr. 1978. Characterization of biological types of cattleCycle II: I. Birth and weaning traits. J. Anim. Sci. 47:1022-1030.

Gregory, K. E., D. B. Laster, L. V. Cundiff, G. M. Smith, and R. M. Koch. 1979a. Characterization of biological types of cattle-Cycle III: II. Growth rate and puberty in females. J. Anim. Sci. 49:461-471.

Gregory, K. E., G. M. Smith, L. V. Cundiff, R. M. Koch, and D. B. Laster. 1979b. Characterization of biological types of cattleCycle III: I. Birth and weaning traits. J. Anim. Sci. 48:271-279.

Johnson, D. L., and R. Thompson. 1995. Restricted maximum likelihood estimation of variance components for univariate normal animal models using sparse matrix techniques and average information. J. Dairy Sci. 78:449-456.

Koch, R. M. 1978. Selection in beef cattle. III. Correlated response of carcass traits to selection for weaning weight, yearling weight and muscling score in cattle. J. Anim. Sci. 47:142-150.

Koch, R. M., L. V. Cundiff, and K. E. Gregory. 1982. Heritabilities and genetic, environmental and phenotypic correlations of carcass traits in a population of diverse biological types and the implications in selection programs. J. Anim. Sci. 55:1319-1329.

Koch, R. M., M. E. Dikeman, D. M. Allen, M. May, J. D. Crouse, and D. R. Campion. 1976. Characterization of biological types of cattle III. Carcass composition, quality and palatability. J. Anim. Sci. 43:48-55.
Koch, R. M., M. E. Dikeman, R. J. Lipsey, D. M. Allen, and J. D. Crouse. 1979. Characterization of biological types of cattleCycle II: III. Carcass composition, quality and palatability. J. Anim. Sci. 49:448-460.

Koch, R. M., L. V. Cundiff, and K. E. Gregory. 1994. Cumulative selection and genetic change for weaning or yearling weight or for yearling weight plus muscle score in Hereford cattle. J. Anim. Sci. 72:864-885.

Koots, K. R., J. P. Gibson, C. Smith and J. W. Wilton. 1994. Analyses of published genetic parameter estimates for beef production traits. 1. Heritability. Anim. Breed. Abst. 62:309-338.

Laster, D. B., G. M. Smith, L. V. Cundiff, and K. E. Gregory. 1979. Characterization of biological types of cattle (Cycle II) II. Postweaning growth and puberty of heifers. J. Anim. Sci. 48:500-508.

Laster, D. B., G. M. Smith, and K. E. Gregory. 1976. Characterization of biological types of cattle IV. Postweaning growth and puberty of heifers. J. Anim. Sci. 43:63-70.

Lee, C., and E. J. Pollak. 1997. Relationship between sire $\times$ year interactions and direct-maternal genetic correlation for weaning weight of Simmental cattle. J. Anim. Sci. 75:68-75.

MacNeil, M. D., L. V. Cundiff, C. A. Dinkel, and R. M. Koch. 1984. Genetic correlations among sex-limited traits in beef cattle. J. Anim. Sci. 58:1171-1180.

Mohuiddin, G. 1993. Estimates of genetic and phenotypic parameters of some performance traits in beef cattle. Anim. Br. Abstr. 61:495-522.

Shanks, B. C., M. W. Tess, D. D. Kress and B. E. Cunningham. 2001. Genetic evaluation of carcass traits in Simmental-sired cattle at different slaughter end points. J. Anim. Sci. 79:595-604.

Smith, G. M., D. B. Laster, and K. E. Gregory. 1976. Characterization of biological types of cattle. I. Dystocia and preweaning growth. J. Anim. Sci. 43:27-36.

Thallman, R. M., L. V. Cundiff, K. E. Gregory, and R. M. Koch. 1999. Germplasm evaluation in beef cattle-Cycle IV: Postweaning growth and puberty in heifers. J. Anim. Sci. 77:2651-2659.

Wheeler, T. L., L. V. Cundiff, R. M. Koch, and J. D. Crouse. 1996. Characterization of biological types of cattle (Cycle IV): Carcass traits and longissimus palatability. J. Anim Sci. 74:1023-1035. 